\title{
Electrical Characterization of Integrated 2-Input TTL NAND Gate at Elevated Temperature, Fabricated in Bipolar SiC-Technology
}

\author{
Muhammad Shakir ${ }^{1, a^{*}}$, Hossein Elahipanah ${ }^{1, b}$, Raheleh Hedayati ${ }^{1, c}$ \\ and Carl-Mikael Zetterling ${ }^{1, d}$ \\ ${ }^{1} \mathrm{KTH}$ Royal Institute of Technology, 16440 Kista, Sweden \\ amshakir@kth.se, bhosseine@kth.se, ${ }^{\mathrm{c}}$ rahelehh@kth.se, ${ }^{\mathrm{d}}$ bellman@kth.se
}

Keywords: TTL NAND gate, bipolar SiC NAND gate, High temperature integrated circuits (ICs), transistor-transistor logic (TTL), SiC ICs, bipolar junction transistor (BJT), digital gate.

\begin{abstract}
This work presents the design and electrical characterization of in-house-fabricated 2-input NAND gate. The monolithic bipolar 2-input NAND gate employing transistor-transistor logic (TTL) is demonstrated in $4 \mathrm{H}-\mathrm{SiC}$ and operates over a wide range of temperature and supply voltage.

The fabricated circuit was characterized on the wafer by using a hot-chuck probe-station from $25^{\circ} \mathrm{C}$ up to $500{ }^{\circ} \mathrm{C}$. The circuit is also characterized over a wide range of voltage supply i.e. 11 to $20 \mathrm{~V}$. The output-noise margin high $\left(\mathrm{NM}_{\mathrm{H}}\right)$ and output-noise margin low $\left(\mathrm{NM}_{\mathrm{L}}\right)$ are also measured over a wide range of temperatures and supply voltages using voltage transfer characteristics (VTC). The transient response was measured by applying two square waves of, $5 \mathrm{kHz}$ and $10 \mathrm{kHz}$. It is demonstrated that the dynamic parameters of the circuit are temperature dependent. The 2-input TTL NAND gate consumes $20 \mathrm{~mW}$ at $500{ }^{\circ} \mathrm{C}$ and $15 \mathrm{~V}$.
\end{abstract}

\section{Introduction}

Silicon based integrated circuits (ICs) have been improved significantly in terms of speed, power, and size, but mainly in the low-temperature range $\left(<\approx 200{ }^{\circ} \mathrm{C}\right)$. At significantly higher temperatures these circuits are susceptible to various issues e.g. thermal runaway, leakage current etc. For the applications such as space exploration, oil and gas drilling, automation and aviation industries we need reliable ICs to work in extreme environment e.g. for Venus surface exploration (surface temperature $\approx 460{ }^{\circ} \mathrm{C}$ ). Silicon carbide ( $\mathrm{SiC}$ ), because of its wide bandgap of $3.2 \mathrm{eV}$ is attractive for elevated temperature and radiation critical applications [1]. Measurement results of digital circuits designed using transistor-transistor logic (TTL) have previously been reported up to $355^{\circ} \mathrm{C}$ [2]. However, many integrated circuits designed using MESFETs, BJTs, or JFETs have been reported working up to $600{ }^{\circ} \mathrm{C}$ [3-5]. Because of its critical gate oxide, the MOSFET is not an ideal candidate for higher temperature applications, which causes reliability issues at higher temperatures. However, CMOS based digital circuits have been reported recently to work up to $470{ }^{\circ} \mathrm{C}[6]$.

\section{Circuit Design, Implementation and Measurement Setup}

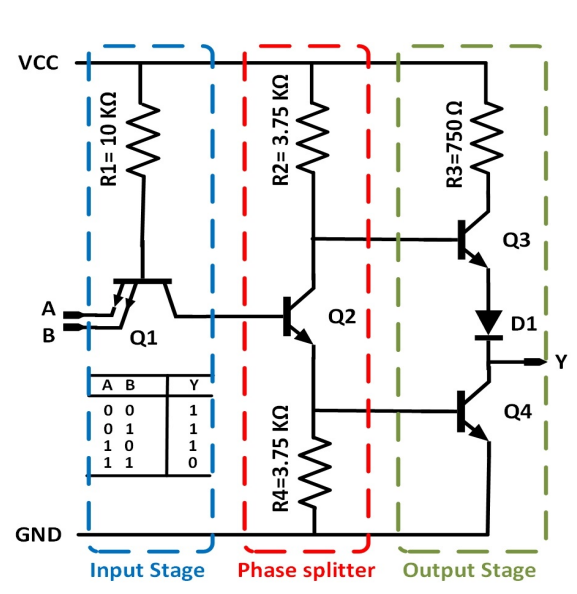

Fig. 1. 2-input TTL NAND gate schematic.

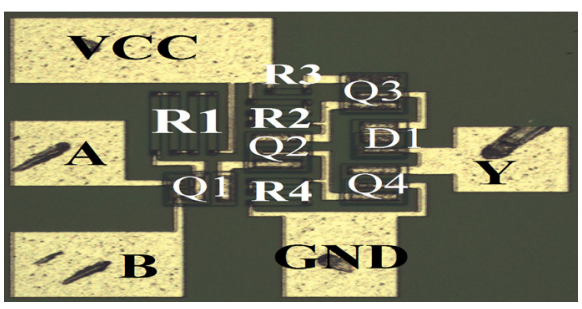

Fig. 2. Micrograph of 2-input TTL NAND gate.

This work presents the design, in-house fabrication and electrical characterization of 2-input NAND gates. The schematic of a 2-input NAND gate designed using TTL is given in Fig. 1. According to the schematic of the TTL NAND gate, it consists of three stages. The first stage is 


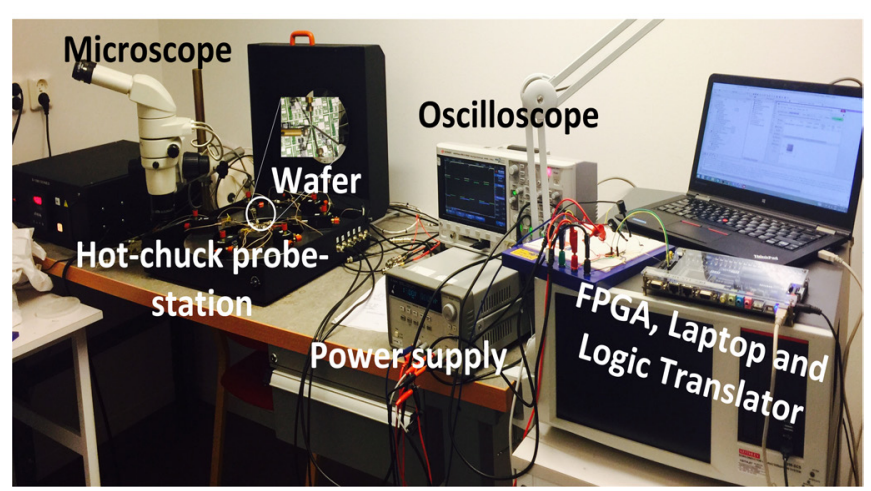

Fig. 3. 2-input NAND gate measurement setup.

called the input stage and it consists of a multiemitter transistor. The second stage is called the phase splitter. In this stage, the transistor is used as a switch and it splits the phase into two parts i.e. 0 and 1 . The third stage is the output stage and it consists of two transistors, both the transistors are on and off in a mutually exclusive way in a totem-pole arrangement. For input combinations $(A=B=0)$ or $(A=0$, $\mathrm{B}=1)$ or $(\mathrm{A}=1, \mathrm{~B}=0)$ the double emitter transistor $\mathrm{Q}_{1}$ is on and therefore $\mathrm{Q}_{2}$ is off which splits the phase into logic 1 at the collector and logic 0 at emitter hence $\mathrm{Q}_{3}$ will be on, $\mathrm{Q}_{4}$ will be off and the output $\mathrm{Y}=1$. For the input combination $\mathrm{A}=\mathrm{B}=1$ the emitter-base junction of $\mathrm{Q}_{1}$ will be reverse biased and it operates in reverse active mode, this makes the phase splitter $\mathrm{Q}_{2}$ change the collector to logic 0 and emitter to logic 1 , and due to this the transistor $\mathrm{Q}_{3}$ is off and $\mathrm{Q}_{4}$ is on hence the final output is at logic 0 . The TTL NAND gate has been implemented using a SiC process design kit (PDK) developed for our inhouse $\mathrm{SiC}$ technology. 4 types of devices have been used to realize the NAND gate i.e. the doubleemitter BJT $Q_{1}$, single-emitter BJTs $\mathrm{Q}_{2,3,4}$, circuit-diode $\mathrm{D}_{1}$ and resistors $\mathrm{R}_{1,2,3,4}$. The micrograph is shown in Fig. 2. A complete TTL digital gate library has been designed and it lays the foundation for complex integrated circuits, such as a microcontroller.

The fabricated circuit was characterized on the wafer by using a hot-chuck probe-station from 25 ${ }^{\circ} \mathrm{C}$ up to $500{ }^{\circ} \mathrm{C}$ for 4 hours, the input signals are generated using an FPGA and the logic level is translated by using commercial-off-the-shelf driver circuits. The output signals are analyzed using oscilloscope. The measurement setup is shown in figure 3 .

\section{Measurement Results}

The transient response from 25 to $500{ }^{\circ} \mathrm{C}$ was measured by applying 2 square waves of $10 \mathrm{kHz}$ and $5 \mathrm{kHz}$ and is shown in figure 4 . The transient response of 2-input NAND gate as an inverter is shown in Fig. 5 made at 25 to $500{ }^{\circ} \mathrm{C}$ by applying the same $10 \mathrm{kHz}$ square wave at both inputs. The measured performance of the NAND gate is summarized in table 1 at 6 discreet temperatures. When the temperature increases up to $200{ }^{\circ} \mathrm{C}$, the output voltage swing remains fairly constant at 11 $\mathrm{V}$, thereafter it increases up to $12.5 \mathrm{~V}$ at $500{ }^{\circ} \mathrm{C}$. The delay almost linearly increases with temperature, since the current gain decreases with temperature. The measured output characteristic of the fabricated BJT at different temperatures is shown in fig. 6. The maximum current gain is reduced from 37 at $25^{\circ} \mathrm{C}$ to 17 at $500{ }^{\circ} \mathrm{C}$, it is expected that the delay will increase.

Fig. 7 shows the voltage transfer characteristics (VTC) of the TTL 2-input NAND gate at different temperatures. The stable operating points are the highest and lowest intersection points of normal and the inverted VTC curves. The noise margin (NM)

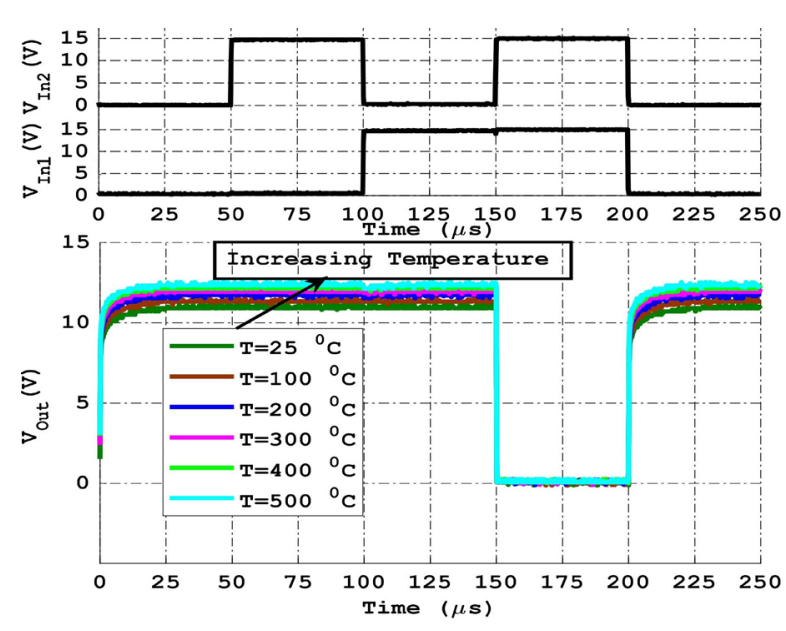

Fig. 4. Measured transient response at $\mathrm{T}=25$ to $500{ }^{\circ} \mathrm{C}\left(\mathrm{f}_{\text {In } 1}=5 \mathrm{kHz}\right.$ and $\left.\mathrm{f}_{\text {In } 2}=10 \mathrm{kHz}\right)$.

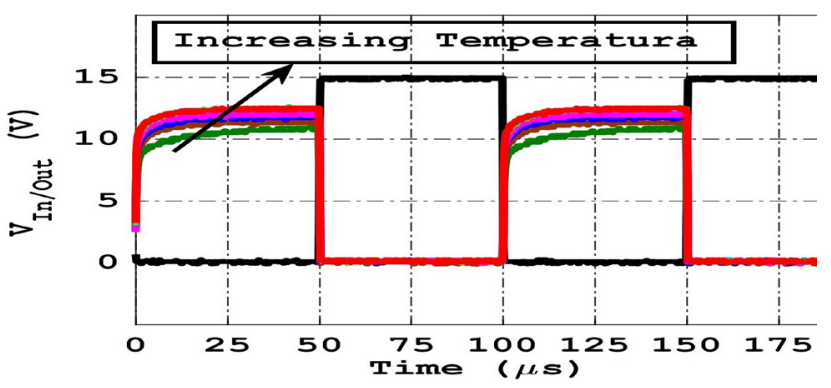

Fig. 5. Measured transient response from $\mathrm{T}=25$. to $500{ }^{\circ} \mathrm{C}$ by applying $\mathrm{f}_{\text {in }}=10 \mathrm{kHz}$ at both inputs. 
is the voltage difference between the stable operating point and the knee of the transfer characteristic, defined as the unity slope point. Fig. 8 shows the variation in NM versus the temperature. As the temperature is increased from 25 to $100{ }^{\circ} \mathrm{C}$, the output-low noise margin $\mathrm{NM}_{\mathrm{L}}$ stays fairly constant at $3.7 \mathrm{~V}$ after that it starts decreasing down to $2 \mathrm{~V}$ at $500{ }^{\circ} \mathrm{C}$. The output-high noise margin $\mathrm{NM}_{\mathrm{H}}$ almost linearly increases from 3.5 to $5.5 \mathrm{~V}$, with temperature increased from, 25 to $300{ }^{\circ} \mathrm{C}$ thereafter, it increases up to $6.3 \mathrm{~V}$ at $500{ }^{\circ} \mathrm{C}$.

Fig. 9 shows the VTC at room temperature and different supply voltages for the 2-input NAND gate, $\mathrm{V}_{\mathrm{OL}}$ fairly remains constant whereas $\mathrm{V}_{\mathrm{OH}}$ almost linearly increases with $\mathrm{V}_{\mathrm{CC}}$. Fig. 10 shows the variation in noise margins with changing power supply voltage from 11 to $20 \mathrm{~V}$ at $\mathrm{T}=25^{\circ} \mathrm{C}$. As the $\mathrm{V}_{\mathrm{CC}}$ increased, the $\mathrm{NM}_{\mathrm{L}}$ only increases $0.6 \mathrm{~V}$

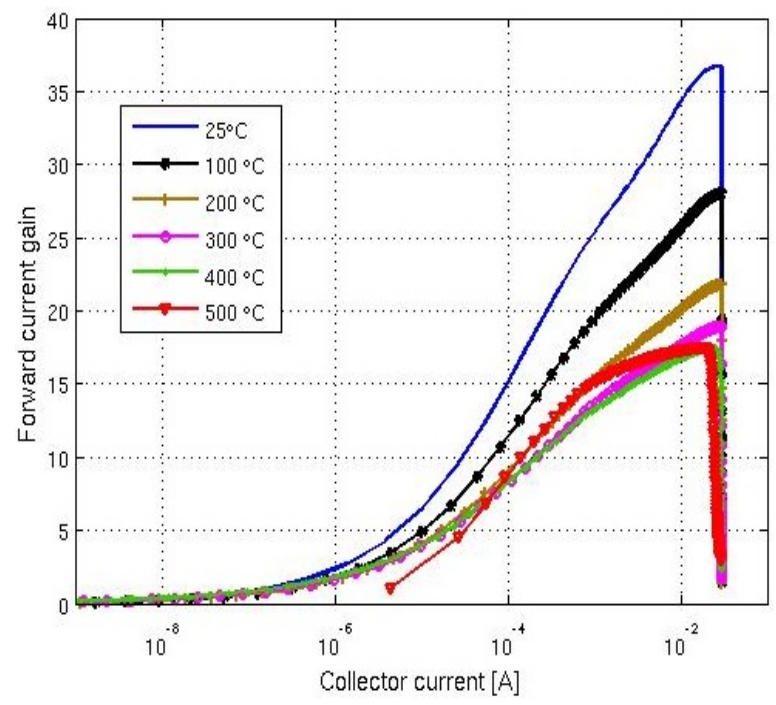

Fig. 6. Measured BJT output characteristics (forward current gain versus collector current at different temperatures). whereas the $\mathrm{NM}_{\mathrm{H}}$ almost linearly increases with $\mathrm{V}_{\mathrm{CC}}$. The $\mathrm{NM}_{\mathrm{L}}$ increases from 3.4 to $4 \mathrm{~V}$ and $\mathrm{NM}_{\mathrm{H}}$ increases from 0 to $7.7 \mathrm{~V}$, as $\mathrm{V}_{\mathrm{CC}}$ goes from 11 to $20 \mathrm{~V}$. As is obvious from Figure 8 and 10, the 2-input TTL NAND gate exhibits adequate noise margins on and above $13 \mathrm{~V}$ of power supply.

Table I. Measured performance of TTL NAND gate over wide temperature range.

\begin{tabular}{ccccc}
\hline Temperature $\left[{ }^{\circ} \mathrm{C}\right]$ & $\mathrm{V}_{\mathrm{OH} / \mathrm{OL}}[\mathrm{V}]$ & $\mathrm{t}_{\text {rise }} / \mathrm{t}_{\text {fall }}[\mathrm{ns}]$ & $\mathrm{t}_{\mathrm{PLH} /} / \mathrm{t}_{\mathrm{PHL}}[\mathrm{ns}]$ & Power $[\mathrm{mW}]$ \\
\hline 25 & $11 / 0.4$ & $484 / 250$ & $220 / 150$ & 30 \\
100 & $11 / 0.1$ & $426 / 270$ & $235 / 170$ & 30 \\
200 & $11 / 0.2$ & $549 / 280$ & $245 / 180$ & 30 \\
300 & $12 / 0.1$ & $486 / 290$ & $255 / 180$ & 25 \\
400 & $12.5 / 0.1$ & $528 / 300$ & $265 / 190$ & 20 \\
500 & $12.5 / 0.1$ & $593 / 300$ & $280 / 200$ & 20 \\
\hline
\end{tabular}

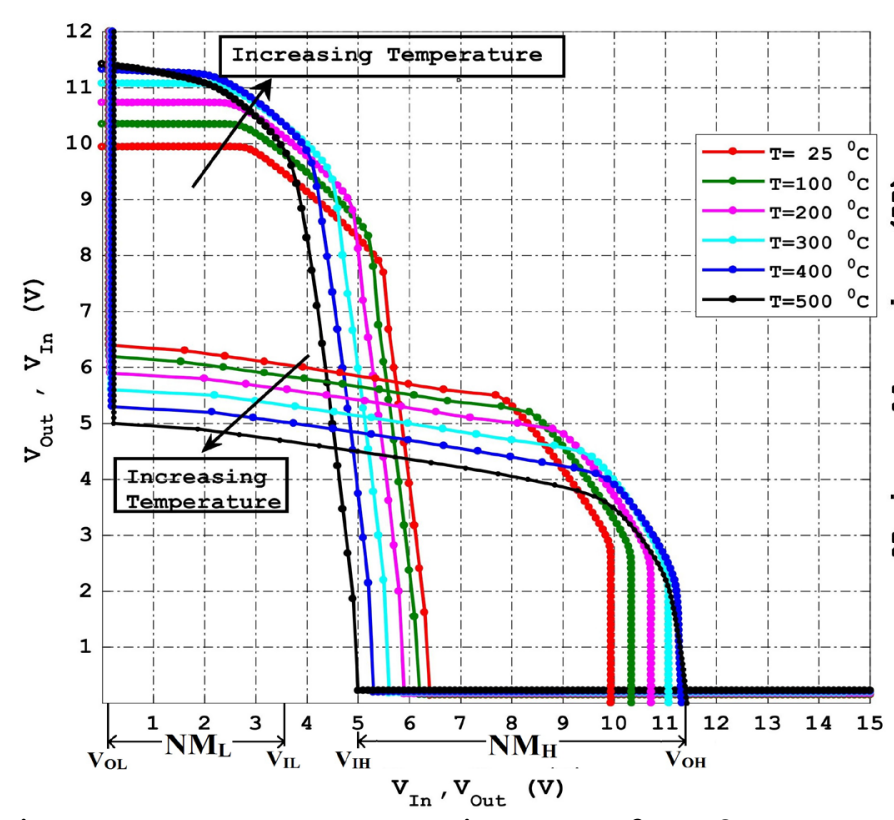

Fig. 7. VTC as temperature increases from 25 to $500{ }^{\circ} \mathrm{C}$ at $\mathrm{V}_{\mathrm{CC}}=14 \mathrm{~V}$.

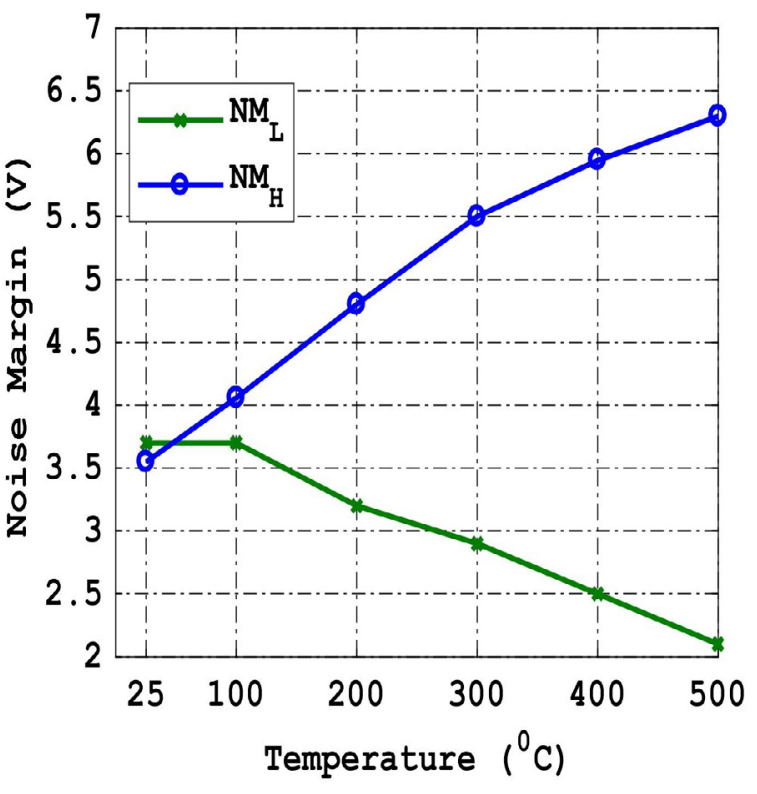

Fig. 8. Noise margins as temperature increases from 25 to $500{ }^{\circ} \mathrm{C}$ at $\mathrm{V}_{\mathrm{CC}}=14 \mathrm{~V}$. 


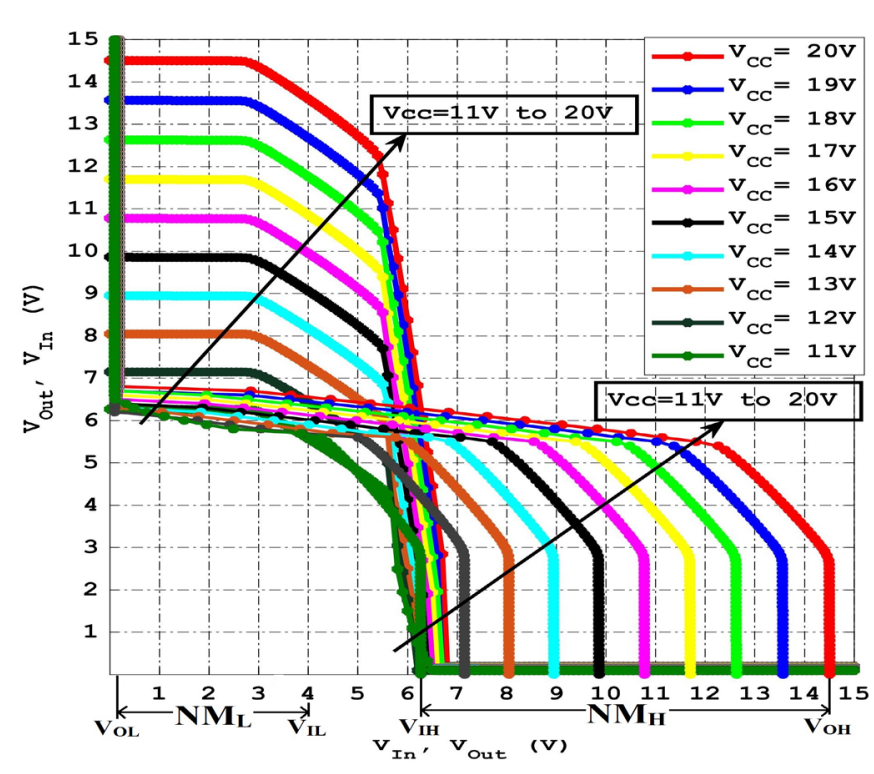

Fig. 9. VTC as supply-voltage goes from 11 to $20 \mathrm{~V}$ at $\mathrm{T}=25^{\circ} \mathrm{C}$.

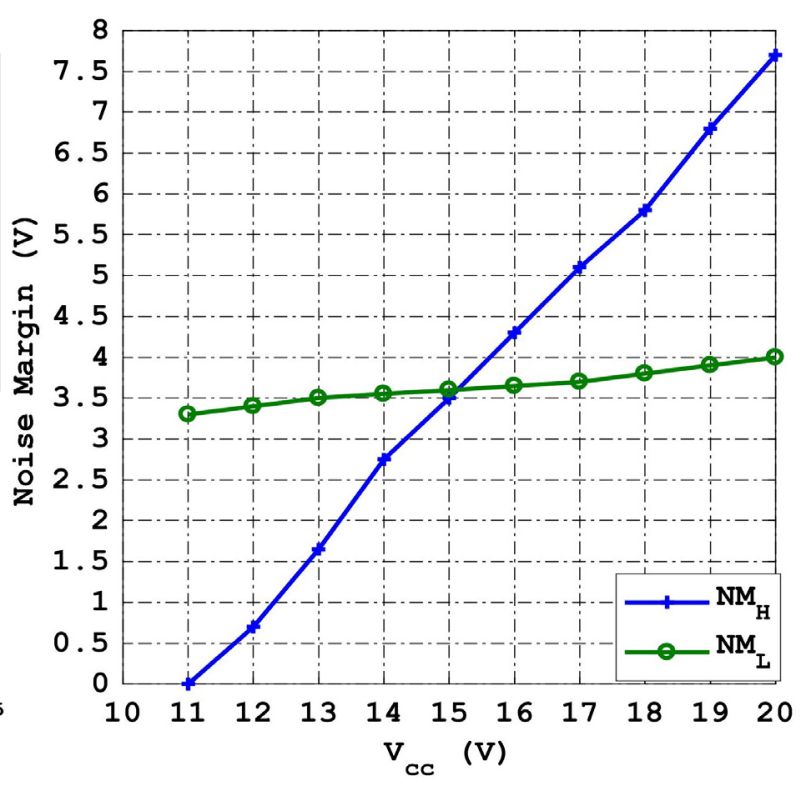

Fig. 10. Noise margins as supply-voltage goes from 11 to $20 \mathrm{~V}$ at $\mathrm{T}=25^{\circ} \mathrm{C}$.

\section{Summary}

A 2-input TTL NAND gate has been successfully designed and characterized over a wide temperature range of 25 to $500{ }^{\circ} \mathrm{C}$. The circuit was also characterized over a wide power supply range. The $\mathrm{DC}$ and transient-response demonstrate that this circuit can be used as a basic gate to realize the complex digital systems that can be employed in extreme environments such as the surface of Venus.

\section{References}

[1] Zetterling, C. (2015). Integrated circuits in silicon carbide for high-temperature applications. MRS Bulletin, 40(5), 431-438. doi:10.1557/mrs.2015.90

[2] S. Singh, J. A. Cooper, Bipolar Integrated Circuits in 4H-SiC. IEEE Transactions on Electron Devices, vol. 58, pp. 1084-1090, 2011

[3] Luigia Lanni, B Gunnar Malm, Mikael Ostling, and Carl-Mikael Zetterling, $500^{\circ} \mathrm{C}$ bipolar integrated OR/NOR gate in 4H-SiC. IEEE Electron Device Letters, 34(9):1091-1093, (Sept. 2013).

[4] R. Hedayati, L. Lanni, M. Shakir, A. Salemi and C. M. Zetterling, "High temperature bipolar master-slave comparator and frequency divider in 4H-SiC technology, " 2016 European Conference on Silicon Carbide \& Related Materials (ECSCRM), Halkidiki, Greece, 2016, pp. 1-1.

[5] A. C. Patil, X. a. Fu, M. Mehregany and S. L. Garverick, "Fully-monolithic, $600^{\circ} \mathrm{C}$ differential amplifiers in 6H-SiC JFET IC technology, " 2009 IEEE Custom Integrated Circuits Conference, San Jose, CA, 2009, pp. 73-76.

[6] Jim Holmes, A. Matthew Francis, Ian Getreu, Matthew Barlow, Affan Abbasi, and H. Alan Mantooth (2016) Extended High-Temperature Operation of Silicon Carbide CMOS Circuits for Venus Surface Application. Journal of Microelectronics and Electronic Packaging: October 2016, Vol. 13, No. 4, pp. 143-154. 